\title{
Stock Market Dispersion and Unemployment
}

\author{
Hui Guo
}

A ccording to the definition used in government statistics, a person who is actively looking for a paying job but is unable to find one is considered to be unemployed. Some positive level of unemployment always exists because (i) firms continually adjust the size of their work force in response to changing business conditions and (ii) it takes time for an unemployed worker to find a new job. It is common to use the unemployment rate-the number of unemployed workers divided by the total civilian labor force-to gauge labor market conditions, and this measure is closely watched by monetary policymakers as well as financial market participants.

The unemployment rate usually rises during business recessions and falls during business expansions; and many economists, e.g., Lilien (1982), argue that sectoral shifts account for a large portion of the cyclical variation in unemployment. ${ }^{1}$ The underlying premise is as follows: When an economy is hit by an adverse shock, e.g., a sharp increase in crude oil prices, then production resources-including labor-will move from more adversely affected sectors to less adversely affected sectors. Because of the presence of industry-specific skills and the time-consuming nature of the job search, the process of transferring workers across industries tends to be slow and involves spells of unemployment. Therefore, an increase in intersectoral shifts leads to higher unemployment by increasing the amount of labor reallocation.

Loungani, Rush, and Tave (1990) suggest that stock market dispersion is a good proxy for the volume of intersectoral shifts. ${ }^{2}$ Intuitively, because stock prices are equal to expected discounted future cash flows, when stock prices in a sector go up (down), the sector is likely to experience increased (decreased) cash flows and thus demand more (less) labor input in the future. Consistent with Lilien's (1982) conjecture, Loungani, Rush, and Tave document a significantly positive relation between stock market dispersion and the future unemployment rate using data for the period 1926-87.

In the accompanying chart, I replicate Loungani, Rush, and Tave's main finding for the period 1964:Q1 to 2006:Q4. The solid line is the log stock market dispersion, which is measured by the value-weighted average realized variance of idiosyncratic shocks to all common stocks included in the CRSP (Center for Research in Security Prices) database; and it is lagged by one year. ${ }^{3}$ The dashed line is the change in the unemployment rate from its level one year ago. As hypothesized, the two variables tend to move in the same direction, with a correlation coefficient of 0.27 . In particular, stock market dispersion appears to provide a good explanation for the movement of the labor market in the past few years. After the spectacular run-up in the second half of 1990s, the prices of information technology stocks collapsed in the year 2000. Such a dramatic intersectoral shift was evidenced by a sharp increase in stock market dispersion; it was also followed by a sharp increase in the unemployment rate. Moreover, the unemployment rate fell at the end of the sample as stock market dispersion eventually receded.

\footnotetext{
${ }^{1}$ Lilien, David M. "Sectoral Shifts and Cyclical Unemployment." Journal of Political Economy, August 1982, 90(4), pp. 773-93.

${ }^{2}$ Loungani, Prakash; Rush, Mark and Tave, William. "Stock Market Dispersion and Unemployment." Journal of Monetary Economics, June 1990, 25(3), pp. 367-88.

${ }^{3}$ The idiosyncratic shock to a stock is the part of its return that is not explained by asset pricing models.
}

\section{Log Stock Market Dispersion vs. Year-Over-Year Change in the Unemployment Rate}

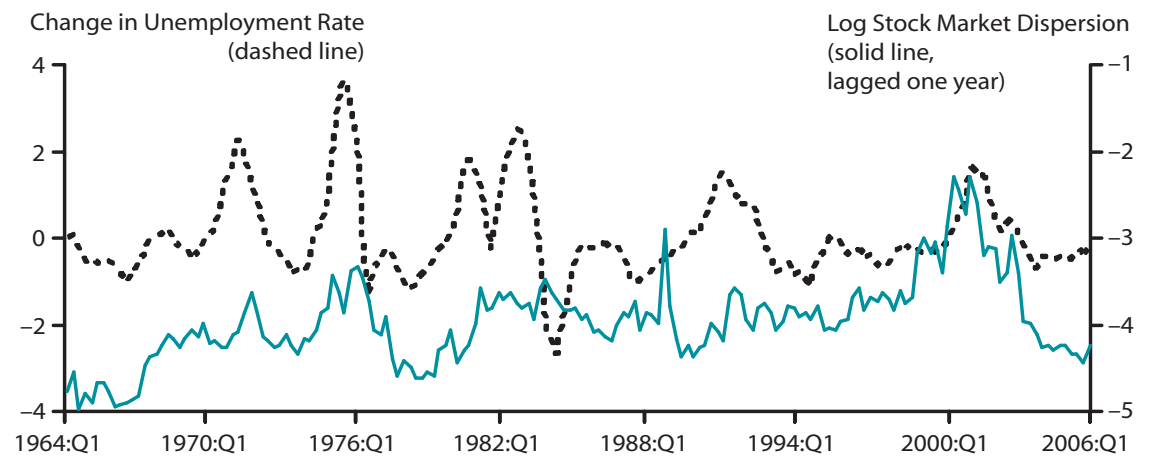

